\title{
HYDRAULICS OF SUBGLACIAL CAVITIES
}

\author{
By JOSEPH S. WALDER
}

(Quaternary Research Center AK-60, University of Washington, Seattle, Washington 98195, U.S.A.)

\begin{abstract}
A theoretical model is developed to describe the steady-state behavior of interconnected, water-filled cavities at the glacier bed. Physically plausible cavities should contain constrictions along the flow path, with flow in the wider sections being relatively sluggish. Mean flow rates in cavities may be at least one order of magnitude less than in channels incised into the basal ice ( $R$ channels). Melting due to viscous dissipation - the process that allows $\mathrm{R}$ channels to exist - probably plays a minor or negligible role, as compared to glacier sliding, in determining the size of cavities. Furthermore, a system of subglacial cavities should not show a tendency for localization of flow in few main conduits, as does an R-channel system. If water pressure rises to within several bars of overburden pressure, the rate of cavity closure by creep falls below the rate of cavity opening by sliding and melting, with cavities then becoming unstable. Subsequent evolution of the drainage system should depend upon the total melt-water flux. Circumstances may arise in which cavities and channels act as conduits for melt water; such a configuration would probably show unusual transient behavior.
\end{abstract}

RÉsumé. L'hydraulique des cavités sous glaciaires. On développe un modèle théorique pour décrire le comportement en état stationnaire des cavités remplies d'eau et interconnectées sur le lit du glacier. Des cavités physiquement plausibles doivent comporter des rétrécissements le long du trajet de l'écoulement, avec un écoulement dans les sections plus larges relativement calme. Les vitesses d'écoulement dans les cavités peuvent être d'au moins un ordre de grandeur plus faible que dans les canaux taillés dans la glace basale (chenaux R). La fonte due à la chaleur de déformation, responsable de l'existence des chenaux $R$, joue probablement un rôle mineur ou même négligeable, en comparaison du glissement du glacier pour le contrôle de la taille des cavités. De plus, un système de cavités sous glaciaires ne devrait pas montrer de tendance à la localisation de l'écoulement en quelques conduits principaux, comme cela se passe dans le système de chenaux

\section{INTRODUCTION}

Basal melt water is widely considered to have a major influence upon the sliding behavior of temperate glaciers. Numerous field studies have demonstrated links between variations in the subglacial drainage network and variations in sliding speed, with enhanced sliding during the melt season a nearly ubiquitous observation. Nonetheless, there has been a lack of consensus as to whether sliding-speed variations are due primarily to the amount of melt water or to the water pressure. Much of this controversy centers on issues of geometry: just how is melt water at the glacier bed distributed? Is melt water transported primarily through conduits, through a widespread, thin sheet, or through permeable till? How might the flow configuration be related to the glacier's dynamic behavior?

Analyses have been developed to describe various aspects of subglacial water flow, both for sheet flow (Weertman, 1972; Walder, 1982; Weertman and Birchfield, $1983[\mathrm{~b}])$ and for flow in channels incised into the basal ice (Röthlisberger, 1972; Shreve, 1972; Weertman, 1972; Nye, 1976; Spring and Hutter, 1981). The subglacial drainage system is likely also to include cavities formed by
R. Si la pression de l'eau croit jusqu'à plusieurs bars près de la valeur de la pression de la glace susjacente, la vitesse de fermeture des cavités par déformation descends en dessous de celle d'ouverture due au glissement et à la fonte: le système des cavités devient alors instable. En conséquence l'évolution du système de drainage doit dépendre du flux total d'eau de fonte. Il peut arriver que les chenaux et cavités soient des conduits d'eau de fonte; une telle situation ferait apparaitre un comportement transitoire non habituel.

ZuSAMMENFASSUng. Hydraulik subglazialer Hohlräume. Zur Beschreibung des stationären Verhaltens von miteinander verbundenen, wassergefüllten Hohlräumen am Gletscherbett wird ein theoretisches Modell entwickelt. Physikalisch mögliche Hohlräume sollten entlang des Fliessweges Einengungen aufweisen, mit relativ trägem Fluss in den weiter geöffneten Abschnitten. Die mittlere Fliessgeschwindigkeit in Hohlräumen dürfte mindestens eine Grössenordnung geringer sein als die in Kanälen, die ins Eis am Untergrund eingeschnitten sind (R-Kanäle). Schmelzen infolge viskoser Dissipation - ein Prozess der die Existenz von R-Kanälen ermöglicht - spielt vermutlich - verglichen mit dem Gletschergleiten - eine geringere oder vernachlässigbare Rolle bei der Bemessung der Hohlraumgrössen. Weiterhin sollte ein System von subglazialen Hohlräumen keine Tendenz zur Einschränkung des Flusses auf einige wenige Hauptführungen zeigen, wie dies bei einem System von R-Kanälen der Fall ist. Steigt der Wasserdruck auf einen Wert innerhalb von einigen bar des Auflastdruckes, so sinkt die Rate der Hohlraumverschlüsse durch Kriechen unter die Rate der Hohlraumöffnungen durch Gleiten und Schmelzen; die Hohlräume werden dann instabil. Die daraus folgende Entwicklung des Abflussystems sollte vom GesamtSchmelzwasserfluss abhängen. Es können Umstände eintreten, unter denen Hohlräume zusammen mit Kanälen als Führungen für Schmelzwasser dienen; eine solche Ausprägung würde aber vermutlich nur ein Übergangsstadium sein.

"separation" of sliding ice from the glacier bed. Lliboutry $(1976,1978,1979)$ has suggested that cavities at temperateglacier beds may be characterized as either "autonomous" storage sites or as forming part of an "interconnected hydraulic regime" draining melt water. Detailed geomorphic mapping of recently deglaciated bedrock surfaces (Walder and Hallet, 1979; Hallet and Anderson, 1980) suggests that "interconnected" cavities form part of a network of anastomosing conduits, the other "segments" of the conduit network being channels incised into the basal ice ( $R$ channels) or into the bed (Nye channels). Recent field studies of glacier dynamics and hydraulics (e.g. Iken and others, 1983; Kamb and others, 1985; Iken and Bindschadler, 1986) also strongly suggest an important role for subglacial cavities in melt-water drainage. This paper describes a theoretical model developed to explain some aspects of water flow through subglacial cavities.

\section{ANALYSIS OF STEADY FLOW IN CAVITIES}

I will focus attention on flow in cavities filled with water such that the water flows "under pressure". Viscous dissipation in the flowing water produces frictional heat that 
tends to melt the cavity walls; at the same time, the cavity will tend to collapse as long as the water pressure is less than the ice-overburden pressure. This is quite analogous to the situation in an $\mathrm{R}$ channel (e.g. Röthlisberger, 1972, p. 178). The cavity will in addition tend to be "opened" by continual sliding of the glacier over its bed. In the steady state, the opening and closing processes must balance. It will turn out that melting is often of secondary importance, compared to sliding, as a cavity-enlarging process. This leads to very significant differences between the hydraulic behavior of $\mathrm{R}$ channels and that of cavities. In particular, the strong tendency for "stream capture" and flow localization in a few large cavities, so characteristic of $\mathrm{R}$ channels (Röthlisberger, 1972; Shreve, 1972), should not exist in a cavity-dominated drainage system.

A major consideration in the present analysis is an idealization of cavity geometry motivated by observations of exhumed melt-water drainage systems on recently deglaciated bedrock (Walder and Hallet, 1979; Hallet and Anderson, 1980; and my observations at Findelengletscher and elsewhere). I assume that cavities are typically elongated along the lee sides of bedrock protuberances, with water typically flowing through cavities in a direction oblique to the local ice-flow direction. The elongated, cavity-like conduits may be linked to each other by short $\mathrm{R}$ channels and Nye channels; furthermore, cavity cross-sections may change along the water-flow direction due to variations in bed topography (cf. Kamb, in press). The result is a complex, tortuous drainage system that largely "avoids" regions of the bed where the normal stress exerted by the ice is large (Fig. 1a). This model differs significantly from the hypothetical situation of cavities joined along the ice-flow direction by $\mathrm{R}$ channels and Nye channels, much like beads on a string (Fig. 1b). The latter scenario requires that channels traverse high-pressure regions on the stoss sides of bed protuberances.
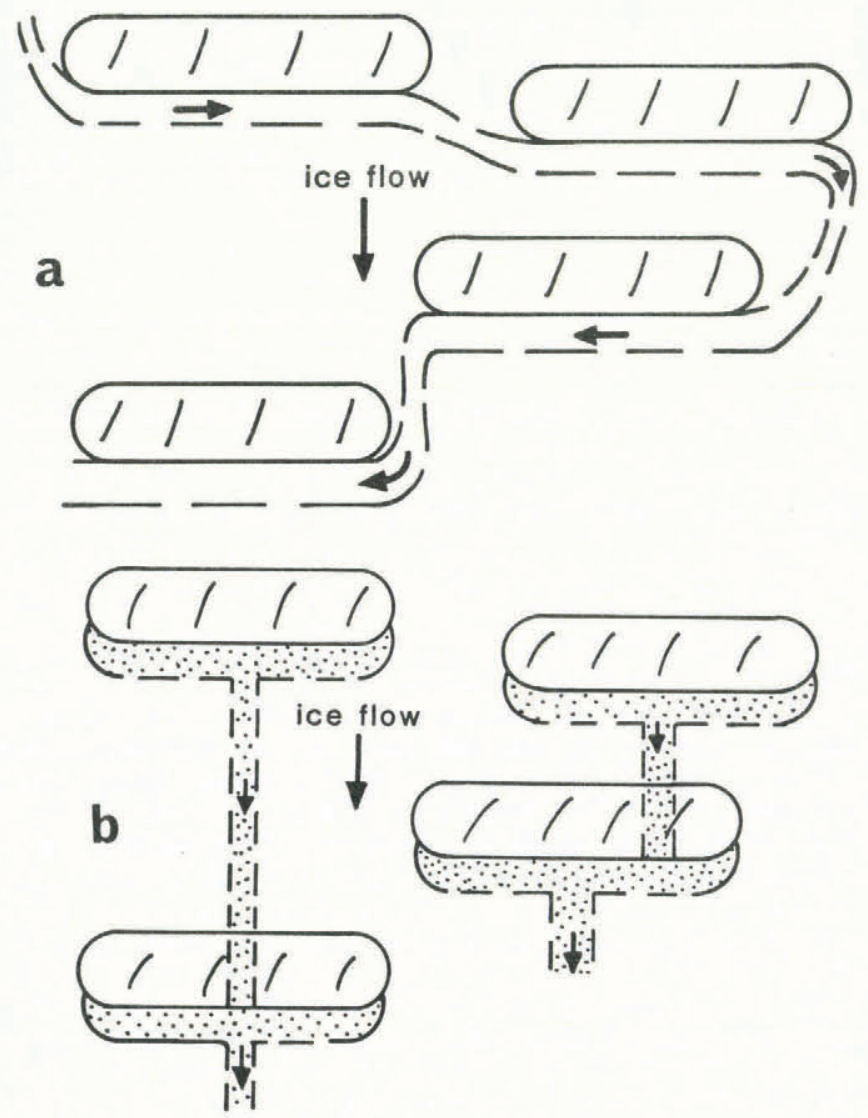

Fig. 1. a. Schematic plan view of basal drainage network. Conduits largely "avoid" high-pressure regions of the bed (hatched).

b. Hypothetical basal drainage system in which channels and cavities connect only along the ice-flow direction, with channels crossing high-pressure regions (hatched). This is probably not a physically plausible configuration.
The model of the subglacial conduit system in Figure 1a is clearly a simplification that leaves out important features of the "real" system. Perhaps the most significant departure from reality is the implicit assumption that the water flow is essentially rectilinear. Real cavities may have more than one "entrance" and "exit", as well as "dead-end" regions that function essentially as storage sites (cf. Walder and Hallet, 1979, fig. 7). Modeling the flow in such a drainage system might be possible by using numerical techniques analogous to those developed for simulating flow in porous media (e.g. Dullien, [ $\left.{ }^{c} 1979\right]$; Seeburger and Nur, 1984; Yale, unpublished). In the present study, however, I am seeking only to elucidate basic features of cavity hydraulics; these should not be grossly affected by the geometrical simplifications introduced into the analysis.

\section{Cavity size}

I now derive an approximate expression for steady-state cavity size in the interconnected regime. (The development here parallels that of Weertman and Birchfield (1983[a], p. 24-25), who considered the case of autonomous cavities.) For clarity, cavities will be assumed to form on the lee sides of "steps" of height $R$ on the bed and to be much longer along the water-flow direction than in any transverse direction (Fig. 2). I will define an "effective cavity-closure rate" $u_{\mathrm{e}}$ as the difference between the rate of closure $u_{\mathrm{c}}$ by creep and the rate of melting $u_{\mathrm{m}}$ of the walls. This effective closure rate will be balanced with the rate of cavity opening by sliding to find the cavity "length" $L$, defined in Figure 2.

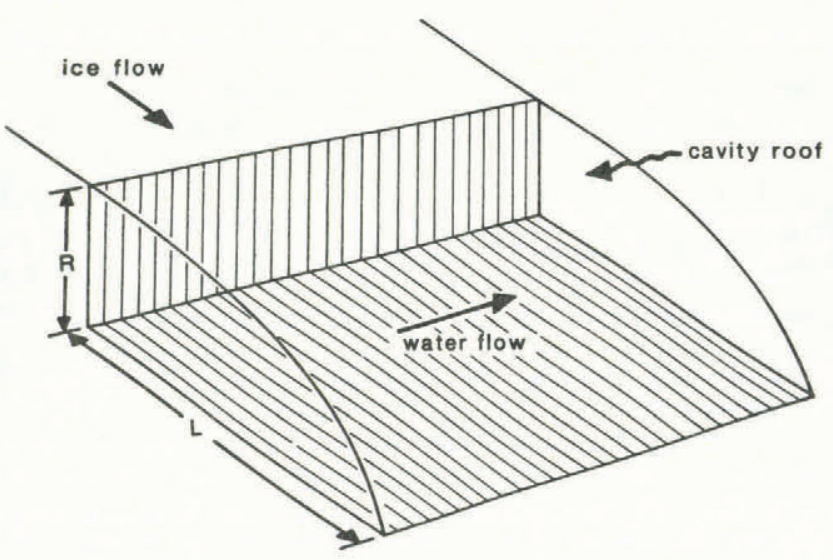

Fig. 2. Idealized cavity geometry. 1953)

The creep-closure rate will be approximately (cf. Nye,

$$
u_{\mathrm{c}}=R\left(\frac{p_{\mathrm{e}}}{n A}\right]^{n}
$$

where $p_{\mathrm{e}}=p_{\mathrm{i}}-p_{\mathrm{w}}$ is the effective pressure, with $p_{\mathrm{i}}$ being approximately the ice-overburden pressure and $p_{\mathrm{w}}$ the water pressure in the cavity; $n$ and $A$ are flow-law parameters for ice (Nye, 1953). The melting rate $u_{\mathrm{m}}$ is given by

$$
u_{\mathrm{m}}=(1-\gamma) \frac{Q G v_{i}}{P H}
$$

where $Q$ is the volumetric flux of water through the cavity; $G$ is the hydraulic gradient (units of $\mathrm{Pa} / \mathrm{m}$ ), assumed constant along the water-flow path; $v_{i}$ is the specific volume of ice; $P$ is the perimeter of the cavity roof for a section transverse to the water-flow direction; and $H$ is the latent heat of fusion per unit mass. The factor $(1-\gamma) \approx 0.68$ corrects for the energy required to maintain the water at the pressure melting-point (Röthlisberger, 1972, p. 179). Implicit in Equation (2) are two assumptions: first, the rate of melting of the cavity roof is spatially uniform; secondly, any frictional heat that flows into the glacier bed eventually causes melting of basal ice in the vicinity of the cavity. 
Combining Equations (1) and (2) gives

$$
u_{\mathrm{e}}=R\left[\frac{p_{\mathrm{e}}}{n A}\right)^{n}-(1-\gamma) \frac{Q G v_{\mathrm{i}}}{P H} .
$$

For simplicity, I will follow Lliboutry (1978) and assume the cavity roof is elliptical in cross-section. $P$ will then generally be given by an elliptic integral, but assuming "well-developed" cavities such that $L>c .3 R$, one may approximate (cf. Selby, [ $\left.{ }^{\mathrm{C}} 1972\right]$, p. 18)

$$
P=k_{1} L
$$

where $k_{1}=\pi / 2^{3 / 2} \approx 1.1$. Note from Equation (3) that, for sufficiently low effective pressure $p_{e}$, the effective closure rate would vanish; hence, no stable, finite-sized cavity could exist. This point will be elaborated later.

Consider now the role of sliding in keeping a cavity open. The time $T_{\mathrm{c}}$ that any "particle" of ice in the cavity roof is separated from the bed is given approximately by

$$
T_{\mathrm{c}}=\frac{R}{u_{\mathrm{c}}}
$$

In this same period of time, the "particle" will have moved (by definition) a distance $L$ along the ice-flow direction. For sliding speed $u_{\mathrm{S}}$, therefore,

$$
L=-\frac{u_{s} R}{u_{\mathrm{e}}}
$$

so combining Equations (3) and (6),

$$
L=\frac{u_{\mathrm{s}} R}{R\left[\frac{p_{\mathrm{e}}}{n A}\right]^{n}-(1-\gamma) \frac{Q G v_{\mathrm{i}}}{P H}} .
$$

For the approximate case of "long" cavities, substitution of Equation (4) into Equation (7) and a bit of re-arrangement leads to the result:

$$
L=\left(u_{\mathrm{s}}+\tilde{u}_{\mathrm{m}}\right)\left(\frac{n A}{p_{e}}\right)^{n}
$$

where $\tilde{u}_{\mathrm{m}}=(1-\gamma) Q G v_{\mathrm{i}} / k_{1} R H$. An interesting feature of this result is that, in comparison to sliding, melting will of ten have a rather minor effect on cavity length. This is indicated in Table $I$, in which values of $\widetilde{u}_{\mathrm{m}}$ are given for several plausible values of flux $Q$, hydraulic gradient $G$ (cf. Appendix), and cavity height $R$. Unless the discharge through a single cavity is a significant fraction of the total melt-water discharge from the glacier, $\tilde{u}_{\mathrm{m}}$ will usually be small in comparison with $u_{\mathrm{s}}$, the sliding speed. Cavity length will then be given approximately by

$$
L \approx u_{\mathrm{s}}\left(\frac{n A}{p_{\mathrm{e}}}\right)^{n} .
$$

TABLE I. EFFECTIVE MELTING RATE $\tilde{u}_{\mathrm{m}}$, IN m/a, FOR FLOW IN CAVITIES OF HEIGHT $R=0.1 \mathrm{~m}$. FOR $\tilde{u}_{m} \ll u_{\mathrm{s}}$, THE SLIDING SPEED, MELTING IS OF NEGLIGIBLE IMPORTANCE IN DETERMINING CAVITY SIZE

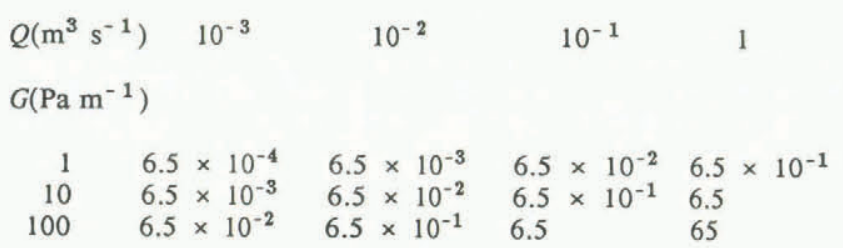

Kamb and others (1985) have also argued that the geometry of interconnected cavities will be primarily determined by water-pressure effects rather than by melting.

Stability characteristics of a cavity-dominated drainage
system

An interesting result bearing on the question of stability of interconnected cavities also follows from Equation (8). Noting first that the cavity's cross-sectional area is approximately equal to $\pi R L / 4$, one may write

$$
S \approx \frac{\pi}{4}\left[R u_{\mathrm{s}}+(1-\gamma) \frac{Q G v_{\mathrm{i}}}{H k_{1}}\right]\left[\frac{n A}{p_{\mathrm{e}}}\right]^{n} .
$$

Assuming turbulent flow, $S$ may also be related to discharge $Q$ by the Manning formula (cf. Nye, 1976, p. 189), which for the cavity may be shown to take the form

$$
Q=c_{1} G^{1 / 2} S
$$

where $c_{1}=\left(\pi R / 4 k_{1}\right)^{2 / 3}(1 / m)\left(v_{\mathrm{w}} / g\right)^{1 / 2}$, with $m$ the Manning roughness coefficient, $v_{\mathrm{w}}$ the specific volume of water, and $g$ the acceleration of gravity. It should be stressed that Equation (10) assumes $G$ to be constant, i.e. there are no constrictions in the cavity. Combining Equations (9) and (10) results in

$$
Q \approx \frac{R u_{\mathrm{S}} G^{1 / 2}}{\left[\frac{4}{\pi c_{1}}\right]\left[\frac{p_{\mathrm{e}}}{n A}\right]^{n}-(1-\gamma) \frac{v_{\mathrm{i}} G^{3 / 2}}{k_{1} H}} .
$$

For comparison, the corresponding expression for a steadystate $\mathrm{R}$ channel may be written as (cf. Röthlisberger, 1972, p. 180)

$$
Q_{\text {channel }}=32 \pi\left(\frac{v_{\mathrm{w}}}{v_{\mathrm{i}}}\right]^{4}\left[\frac{H}{g}\right]^{4}\left[\frac{p_{\mathrm{e}}}{n A}\right]^{4 n} m^{3}\left[\frac{g}{v_{\mathrm{w}} G}\right]^{11 / 2} .
$$

Equation (11) has two important consequences. First, it shows that in the steady state, the greater the discharge, the greater must be the pressure gradient, for fixed $p_{\mathrm{e}}$. This is precisely opposite to the steady-state behavior of $\mathrm{R}$ channels (Röthlisberger, 1972, p. 180) and has important consequences for evolution of the drainage network. Should two cavities empty into a common "sink", then up-stream of that point, water pressure in the cavity carrying the greater discharge will be more than that in the cavity carrying the lesser discharge. Hence, "capture" of melt water by a few main conduits is strongly disfavored for the sort of interconnected cavities envisaged here. A system of relatively small conduits distributed over much of the glacier bed would be stable, in accordance with conclusions reached by Kamb and others (1985). This theoretical prediction is in good accord with field studies of former subglacial drainage conduits exposed on recently deglaciated bedrock (Walder and Hallet, 1979; Hallet and Anderson, 1980). These studies clearly indicated that there had been no long-term tendency for development of arborescence in drainage systems dominated by cavities and Nye channels.

I have previously alluded to the second major consequence of Equation (11), namely, that for $p_{\mathrm{e}}$ below a certain value, there will be no stable, finite-sized interconnected cavities, i.e. the effective cavity closure rate $u_{\mathrm{e}}$ will vanish. It may be shown that this condition is equivalent to setting the denominator of Equation (11) equal to zero. "Permissible" steady-state values of $p_{\mathrm{e}}$ are therefore given by the expression

$$
p_{\mathrm{e}} \geqslant c_{2} G^{3 / 2 n} R^{2 / 3 n} n A m^{-1 / n}
$$

where

$$
c_{2}=\left[\left(\pi / 4 k_{1}\right)\left(v_{\mathrm{i}} / H\right)\left(v_{\mathrm{w}} / g\right)^{1 / 2}\right]^{1 / n} .
$$


The lower limit on allowable values of $p_{\mathrm{e}}$, which I will denote by $p_{\mathrm{e}}^{\mathrm{min}}$, should be in the range of physically reasonable values. To calculate $p_{\mathrm{e}}{ }^{\mathrm{min}}$, I take the flow-law parameters $n$ and $A$ to be 3 and $5.14 \times 10^{7} \mathrm{~Pa} \mathrm{~s}^{1 / 3}$, respectively (Lliboutry, 1983, p. 220 ). $R$ is probably on the order of $0.1 \mathrm{~m}$, a value suggested by measurements of uplift of glacier surfaces (Iken and others, 1983; Kamb and others, 1985; Iken and Bindschadler, 1986) and by observations of deglaciated bedrock (Walder and Hallet, 1979; Hallet and Anderson, 1980); the weak dependence of $p_{\mathrm{e}}{ }^{\min }$ on $R$ $\left(p_{\mathrm{e}}{ }^{\min } \propto R^{2 / 9}\right.$ for $\left.n=3\right)$ means that a ten-fold change in $R$ will change $p_{\mathrm{e}}{ }^{\min }$ by a factor of only about 1.7 . The Manning roughness is probably on the order of $0.1 \mathrm{~m}^{-1 / 3} \mathrm{~s}$ (Röthlisberger, 1972, p. 181, table I). Estimation of the hydraulic potential gradient $G$ is somewhat more problematical. The tortuous flow paths in an interconnected cavity system will reduce $G$ below the values of $c .10^{2}-10^{3} \mathrm{~Pa} / \mathrm{m}$ that would likely obtain in $\mathrm{R}$ channels along the ice-flow direction (e.g. Weertman, 1972, p. 293). Moreover, the likely existence of constrictions in the cavity network may have a large effect on $G$ in the "wide" cavities on which we are focusing; as shown in the Appendix, much of the hydraulic potential drop may occur in fairly short constrictions (as also stressed by Kamb (in press)). I therefore estimate $G$ to be c. $10-10^{2} \mathrm{~Pa} / \mathrm{m}$ in the "wide" cavities. Using the above estimates and taking $v_{\mathrm{i}}=1.1 \times 10^{-3} \mathrm{~m}^{3} \mathrm{~kg}^{-1}$, $v_{\mathrm{w}}=10^{-3} \mathrm{~m}^{3} \mathrm{~kg}^{-1}, g=9.8 \mathrm{~m} \mathrm{~s}^{-2}, \quad m=0.1 \mathrm{~m}^{-1 / 3} \mathrm{~s}, \quad$ and $H=3.3 \times 10^{5} \mathrm{~J} \mathrm{~kg}^{-1}$, one finds

$$
p_{\mathrm{e}}^{\min } \approx 1.8-5.7 \times 10^{5} \mathrm{~Pa}(1.8-5.7 \text { bar }) .
$$

The upper bound on this estimate seems somewhat large certainly, smaller values of $p_{\mathrm{e}}$ have been measured at glaciers that are apparently not behaving unstably (e.g. Engelhardt and others, 1978) - but the estimated values of $p_{\mathrm{e}}{ }^{\min }$ are certainly in the range of physically plausible values.

The notion of a water-pressure threshold at which interconnected cavities would become unstable was apparently first advanced by Iken (1981, p. 34). On the basis of simple force-balance arguments rather than any explicit model of cavity formation, Iken gave the minimum effective pressure for cavity stability on a "wavy" bed as

$$
p_{\mathrm{e}}^{\min }=\frac{\tau}{\tan \delta_{\max }}
$$

where $\tau$ is the basal shear stress and $\delta_{\max }$ is "the angle between the steepest tangent on the stoss faces of bed obstacles and the mean bed slope". For $\tau$ on the order of $0.1 \mathrm{MPa}(1 \mathrm{bar})$ and $\delta_{\max }$ no more than a few tens of degrees, $p_{\mathrm{e}}^{\min }$ from this criterion would probably be less than c. $1 \mathrm{MPa}$ (10 bar).

$\mathrm{Kamb}$ (in press) has proposed that an interconnected cavity system will be unstable to pressure perturbations at sufficiently high water pressure. Based on a formal analysis of cavity formation rather more complex than presented above, Kamb predicted that (in our notation)

$$
p_{\mathrm{e}}^{\min \propto \frac{G R^{7 / 3} \eta_{\mathrm{i}}}{u_{\mathrm{s}} m^{2}}}
$$

where $\eta_{i}$ is the effective linear viscosity of the ice. Equation (13) and Kamb's expression (Equation (15)) are similar, though not identical, for $n=1$ (in which case $A$ is equal to $\eta_{\mathrm{i}}$ ). One obvious difference between the two expressions is that sliding speed $u_{\mathrm{s}}$ does not enter explicitly into Equation (13). This might be related to the fact that, unlike Kamb, I have not explicitly examined the hydraulics of the constrictions between cavities. Kamb has argued that such constrictions (which he calls "wave cavities") differ significantly in their hydraulic characteristics from the larger "step cavities" (cavities typically formed at the lee of bedslope discontinuities) that I have analyzed here

Despite uncertainty over the detailed nature of the parameters controlling the instability, it does seem clear that a system of interconnected cavities will be unstable at sufficiently high water pressure. It seems probable that, if the water pressure in an interconnected cavity system rose to values high enough to stop cavity closure, the amount of ice-bedrock separation would increase rapidly, lowering the effective bed roughness and causing accelerated sliding (Iken, 1981; Iken and others, 1983; Iken and Bindschadler, 1986). It is likely that flow through the interconnected cavities could be "short-circuited" by rapidly growing $R$ channels oriented along the ice-flow direction. "Leakage" of water from cavities by way of a thick water sheet is less likely because of adverse pressure gradients near cavity margins (cf. Röthlisberger and Iken, 1982); moreover, any sheet-like leakage would be unstable relative to channelized leakage (Walder, 1982).

I suggest that, once the "short-circuits" develop, the drainage network will evolve along one of two paths. In the first, which is related to the scenario proposed by Kamb (in press) in relation to glacier-surge termination, the newly created $\mathrm{R}$ channels rapidly grow and capture the melt water previously carried by the interconnected cavities. An arborescent network of $R$ channels develops. This is probable only if the total melt-water discharge through these unfavorably situated $R$ channels (which must cross high-pressure regions of the bed) remains very large, leading to the high melting rates necessary to overcome the relatively high rates of creep closure. If the melt-water discharge is not sufficiently high, the drainage system will evolve differently; either newly formed $R$ channels will be squeezed shut before an arborescent R-channel network has time to develop, or such a network may form, but only temporarily. Collapse of these $R$ channels will essentially restore the former interconnected cavity system. This latter evolutionary path resembles that suggested by Iken and others (1983, p. 36). It is also noteworthy that Iken and Bindschadler (1986) found the $u_{\mathrm{S}}$ versus $p_{\mathrm{w}}$ relationship at Findelengletscher is essentially time-invariant, despite the occurrence of several large perturbations caused by downglacier propagating disturbances in the subglacial drainage network. Apparently, this network, which Iken and Bindschadler concluded is cavity-dominated, was able to recover from the effects of the high-pressure disturbances.

\section{Flow rates in the subglacial drainage system}

The rate of movement of melt water through the subglacial drainage system, as determined from dye-tracer studies, has been used to infer characteristics of that system (e.g. Stenborg, 1969; Krimmel and others, 1973; Burkimsher, 1983). It is important to recognize that flow rates may be quite different for various drainage configurations.

The mean flow rate $\bar{U}$ for a conduit may generally be defined as

$$
\bar{U}=\frac{Q}{S}
$$

where $Q$ is the volumetric flux and $S$ is the cross-sectional area. For a cavity, Equation (10) implies that

$$
\bar{U}_{\text {cavity }}=\left(\frac{\pi}{4 k_{1}}\right]^{2 / 3}\left[\frac{\nu_{\mathrm{w}} G_{\text {cavity }}}{g}\right]^{1 / 2} R^{2 / 3} m^{-1}
$$

Before estimating numerical values for $\bar{U}_{\text {cavity }}$, it is critical to recognize that any physically plausible cavity system will have constrictions in which the flow cross-section is greatly reduced (cf. Kamb, in press; see also field studies by Walder and Hallet (1979) and by Hallet and Anderson (1980)). As shown in the Appendix, the occurrence of such constrictions nearly always leads to the condition

$$
\bar{U}_{\text {cavity }} \approx \bar{U}_{\text {wide }}
$$

where the subscript "wide" refers to the relatively wide sections of the cavity. I therefore restrict the discussion to those sections. It is also shown in the Appendix that the hydraulic gradient in the wide sections satisfies the condition

$$
G_{\text {wide }} \ll G_{\text {channel }}
$$


for an R channel oriented along the ice-flow direction. It is plausible that $G_{\text {wide }}$ is one or two orders of magnitude smaller than $G_{\text {channel }}$.

Table II gives values of $\bar{U}_{\text {evity }}$ for plausible values of $G_{\text {cavity }}$ and $R$, with the other parameter values as before. It is clear that the mean flow rate in a cavity system may be

TABLE II. MEAN FLOW RATE IN SUBGLACIAL CAVITIES AS A FUNCTION OF HYDRAULIC GRADIENT $G$ AND CAVITY HEIGHT $R$. EXCEPT FOR VERY LARGE CAVITIES AT IMPLAUSIBLY LARGE HYDRAULIC GRADIENTS, MEAN FLOW RATES ARE MUCH LESS THAN FOR R CHANNELS AT THE SAME $G$ AND WITH THE SAME CONDUIT CROSS-SECTIONAL AREA

$G\left(\mathrm{~Pa} \mathrm{~m}^{-1}\right)$

$R(\mathrm{~m})$

$\begin{array}{lll}0.01 & 1.2 \times 10^{-2} & 2.6 \times 10^{-2} \\ 0.05 & 3.5 \times 10^{-2} & 7.8 \times 10^{-2} \\ 0.1 & 5.5 \times 10^{-2} & 1.6 \times 10^{-1} \\ 0.25 & 1.0 \times 10^{-1} & 2.3 \times 10^{-1} \\ 0.50 & 1.6 \times 10^{-1} & 3.6 \times 10^{-1}\end{array}$

on the order of $0.1 \mathrm{~m} / \mathrm{s}$ or less for many plausible situations. Such values are definitely on the lower end of the range of $\bar{U}$ values inferred from dye-tracer studies (Burkimsher, 1983, p. 404). Substantially higher $\bar{U}$ values are likely in an R-channel system, as I show next.

For a semi-circular $R$ channel, one may use the Manning equation as expressed by Nye (1976, p. 189) to write

$$
\bar{U}_{\text {channel }}=(2 \pi)^{-2 / 3}\left[\frac{v_{\mathrm{W}} G_{\text {channel__ }}}{g}\right]^{1 / 2} S^{1 / 3} m^{-1} .
$$

Consider now the relative values of $\bar{U}$ for a cavity and $\mathrm{R}$ channel of the same cross-sectional area $S$. For fluxes low enough that melting plays a negligible role in determining cavity size, Equation (9) indicates that

$$
S \approx\left[\frac{\pi R u_{\mathrm{s}}}{4}\right]\left[\frac{n A}{p_{\mathrm{e}}}\right]^{n} .
$$

Substituting Equation (21) into Equation (20) and comparing to Equation (17), one finds

$$
\frac{\bar{U}_{\text {cavity }}}{\bar{U}_{\text {channel }}}=\pi k_{1}{ }^{-2 / 3}\left(\frac{G_{\text {cavity }}}{G_{\text {channel }}}\right]^{1 / 2}\left(\frac{R}{u_{\mathrm{s}}}\right)^{1 / 3}\left[\frac{p_{\mathrm{e}}}{n A}\right]^{n / 3} .
$$

Suppose that $G_{\text {cavity }} / G_{\text {channel }}=0.05, \quad R=0.1 \mathrm{~m}$, $u_{\mathrm{S}}=10^{2} \mathrm{~m} / \mathrm{a}$, and that $k_{1}, n$, and $A$ have values as given above. One then calculates

$$
\frac{\bar{U}_{\text {cavity }}}{\bar{U}_{\text {channel }}} \approx 1.35 \times 10^{-1} p_{\mathrm{e}}
$$

where $p_{\mathrm{e}}$ is expressed in MPa. For plausible effective pressures in the range $0.1-2 \mathrm{MPa}(1-20 \mathrm{bar})$,

$$
\frac{\bar{U}_{\text {cavity }}}{\bar{U}_{\text {channel }}} \approx 0.01-0.27 \text {. }
$$

The relative fluxes $Q_{\text {cavity }} / Q_{\text {channel }}$ will be equal to $\bar{U}_{\text {cavisy }}$ $\bar{U}_{\text {channel }}$, because equal cross-sections have been assumed for the two types of conduit.

One may conclude from this development that the mean flow rate in a cavity system may be much less than in an R-channel system and that, for equal melt-water discharges, a cavity-dominated system must contain many more conduits than a system dominated by $R$ channels. These conclusions accord with those reached by Kamb and others (1985, p. 476-78) in their study of the surge of Variegated Glacier. Their interpretation of the measured change in $U$ (from surging to non-surging states) as reflecting a change in the subglacial hydraulic system from cavity-dominated to channel-dominated is consistent with the analysis presented above.

\section{Discussion: cavity-channel interaction}

It is interesting to consider how a channel-dominated basal drainage system might change spatially to a cavitydominated system. Suppose that an R channel "entering" a bed region in which cavities exist is successively "tapped" by a number $N$ of such cavities. I have demonstrated above that a cavity of cross-sectional area comparable to that of a channel will typically carry a much smaller discharge (by one or two orders of magnitude) than the channel. Hence, unless the cavities are quite large compared to the channels or a very large number of cavities exist and tap the channels, some channels should "survive" in cavity-dominated regions. Surviving channels might shrink in cross-section in response to decreased discharge, or might pass into openchannel flow sufficiently near the glacier margins (e.g. Hooke, 1984).

The notion of coexisting basal cavities and $\mathbf{R}$ channels is supported by some field observations. Mapping of deglaciated bedrock by Walder and Hallet (1979) indicated that the basal drainage system beneath the cirque glacier studied contained both cavities and Nye channels. The latter would almost certainly have been accompanied by $R$ channels if oriented along the ice-flow direction (the most common orientation); some of those trending oblique to the ice-flow direction might also have been accompanied by $R$ channels (cf. Hooke, 1984).

Basal zones containing both $R$ channels and interconnected cavities might exhibit somewhat unstable behavior, due to the contrasting $Q$ versus $p_{\mathrm{e}}$ relationships of the two types of conduit (cf. Equations (11) and (12)). Consider, for example, the response to an increase in melt-water discharge. In order for cavities to handle the additional melt water, they would have to enlarge under enhanced water pressure. Channels would also have to enlarge, initially at enhanced $p_{\mathrm{w}}$ (Röthlisberger, 1972, p. 198) but would stabilize at a lower $p_{\mathrm{w}}$ than initially. The channels might then tend to "recapture" melt-water discharge from the cavities. In the extreme case, $R$ channels would grow and recapture all discharge from the cavities. Behavior along these lines might be involved in the termination of glacier surges (Kamb and others, 1985). In any case, it seems probable that glacier-bed regions containing both cavities and $\mathrm{R}$ channels will show fluctuations in water pressure and sliding speed as cavities and channels expand and contract in response to changing melt-water discharge. It is tempting to speculate that such phenomena are related to water-pressure and sliding-speed fluctuations observed at various glaciers (e.g. Engelhardt and others, 1978; Iken and others, 1983; Iken and Bindschadler, 1986)

\section{CONCLUSIONS}

The increasing recognition of the important role of subglacial cavities in glacier hydraulics and dynamics has motivated the analysis presented here. This simple analysis demonstrates that the hydraulics of subglacial cavities should be quite distinct from that of conduits incised into basal ice; specifically, the flux versus pressure relationships and the stability characteristics of the two drainage systems should be quite different. This work constitutes only an initial step in understanding the hydraulics of subglacial cavities. Additional developments must include considering more reasonable geometries for the cavity network as a whole; analysis of the behavior of the constrictions between cavities (Kamb, in press) must be coupled with realistic estimates of the distribution of such constrictions on real glacier beds. Iken and Bindschadler (1986) and Kamb (in press) have suggested that the overall "connectivity" of the cavity system will vary with water pressure, with possibly important implications for the way in which dye tracers will move through the system. 
The transient hydraulic response of subglacial cavities must also be analyzed. This analysis will necessarily be complicated by the need to treat the connectivity of the cavity system as time-dependent. Some beginnings at analyses of this type, with the aim of explaining the propagation of wave-like transients in the subglacial drainage system, have been recently reported by M. Fahnestock and B. Kamb (personal communication). Coupled with this work should be analyses of the transient glacier-sliding behavior induced by hydraulic transients. Such work should lead to a better understanding of the observed time differences between, say, peaks in water pressure and in sliding speed.

\section{ACKNOWLEDGEMENTS}

This work was begun in 1984 while I was with the Project Office-Glaciology of the U.S. Geological Survey, Tacoma, Washington. I am grateful to $\mathrm{Dr}$ M. Meier for providing me with the opportunity to spend several months with the Project Office, as well as for his comments on this work during early stages in its development. I am also pleased to thank C. Raymond, N. Humphrey, B. Hallet, H. Röthlisberger, and an anonymous referee for comments on earlier versions of this manuscript.

\section{REFERENCES}

Burkimsher, M. 1983. Investigations of glacier hydrological systems using dye tracer techniques: observations at Pasterzengletscher, Austria. Journal of Glaciology, Vol. 29, No. 103 , p. 403-16.

Dullien, F.A.L. [ $\left.{ }^{\mathrm{c}} 1979.\right]$ Porous media: fluid transport and pore structure. New York, etc., Academic Press.

Engelhardt, H.F., and others. 1978. Basal sliding and conditions at the glacier bed as revealed by bore-hole photography, by H.F. Engelhardt, W.D. Harrison, and B. Kamb. Journal of Glaciology, Vol. 20, No. 84, p. 469-508.

Hallet, B., and Anderson, R.S. 1980. Detailed glacial geomorphology of a proglacial bedrock area at Castleguard Glacier, Alberta, Canada. Zeitschrift für Gletscherkunde und Glazialgeologie, Bd. 16, Ht. 2, p. 171-84.

Hooke, R.L. 1984. On the role of mechanical energy in maintaining subglacial water conduits at atmospheric pressure. Journal of Glaciology, Vol. 20, No. 105, p. 180-87.

Iken, A. 1981. The effect of the subglacial water pressure on the sliding velocity of a glacier in an idealized numerical model. Journal of Glaciology, Vol. 27, No. 97 , p. 407-21.

Iken, A., and Bindschadler, R.A. 1986. Combined measurements of subglacial water pressure and surface velocity of the Findelengletscher, Switzerland: conclusions about drainage system and sliding mechanism. Journal of Glaciology, Vol. 32, No. 110, p. 101-19.

Iken, A., and others. 1983. The uplift of Unteraargletscher at the beginning of the melt season - a consequence of water storage at the bed? By A. Iken, H. Röthlisberger, A. Flotron, and W. Haeberli. Journal of Glaciology, Vol 29, No. 101 , p. 28-47.

$\mathrm{Kamb}$, B. In press. An observationally based mechanism of glacier surging. International workshop on hydraulic effects at the glacier bed and related phenomena, Interlaken, Switzerland, 16-19 September 1985. [Abstract.]

Kamb, B., and others. 1985. Glacier surge mechanism: 1982-1983 surge of Variegated Glacier, Alaska, by B. Kamb [and 7 others]. Science, Vol. 227, No. 4686, p. 469-79.

Krimmel, R.M., and others. 1973. Water flow through a temperate glacier, by R.M. Krimmel, W.V. Tangborn, and M.F. Meier. (In [International Hydrological Decade.] The role of snow and ice in hydrology. Proceedings of the Banff symposia, September 1972. A contribution to the International Hydrological Decade. Paris, UNESCO; Geneva, WMO; Budapest, IAHS, Vol. 1, p. 401-16 (Publication No. 107 de l'Association Internationale d'Hydrologie Scientifique.))

Lliboutry, L. 1976. Physical processes in temperate glaciers. Journal of Glaciology, Vol. 16, No. 74, p. 151-58.
Lliboutry, L. 1978. Glissement d'un glacier sur un plan parsemé d'obstacles hémisphériques. Annales de Géophysique, Tom. 34, Fasc. 2, p. 147-62.

Lliboutry, L. 1979. Local friction laws for glaciers: a critical review and new openings. Journal of Glaciology, Vol. 23, No. 89, p. 67-95.

Lliboutry, L. 1983. Modifications to the theory of intraglacial waterways for the case of subglacial ones. Journal of Glaciology, Vol. 29, No. 102, p. 216-26.

Nye, J.F. 1953. The flow law of ice from measurements in glacier tunnels, laboratory experiments and the Jungfraufirn borehole experiment. Proceedings of the Royal Society of London, Ser. A, Vol. 219, No. 1139, p. 477-89.

Nye, J.F. 1976. Water flow in glaciers: jökulhlaups, tunnels and veins. Journal of Glaciology, Vol. 17, No. 76, p. 181-207.

Röthlisberger, H. 1972. Water pressure in intra- and subglacial channels. Journal of Glaciology, Vol. 11, No. 62 , p. $177-203$.

Seeburger, D.A., and Nur, A. 1984. A pore space model for rock permeability and bulk modulus. Journal of Geophysical Research, Vol. 89, No. B1, p. 527-36.

Selby, S.M., ed. [ [ ${ }^{1972 .] ~ S t a n d a r d ~ m a t h e m a t i c a l ~ t a b l e s . ~ 20 t h ~}$ edition. Cleveland, OH, Chemical Rubber Company.

Shreve, R.L. 1972. Movement of water in glaciers. Journal of Glaciology, Vol. 11, No. 62, p. 205-14.

Spring, U., and Hutter, K. 1981. Numerical studies of jökulhlaups. Cold Regions Science and Technology, Vol. 4, No. 3, p. 227-44.

Stenborg, T. 1969. Studies of the internal drainage of glaciers. Geografiska Annaler, Vol. 51A, Nos. 1-2, p. 13-41.

Walder, J.S. 1982. Stability of sheet flow of water beneath temperate glaciers and implications for glacier surging. Journal of Glaciology, Vol. 28, No. 99, p. 273-93.

Walder, J.[S.], and Hallet, B. 1979. Geometry of former subglacial water channels and cavities. Journal of Glaciology, Vol. 23, No. 89, p. 335-46.

Weertman, J. 1972. General theory of water flow at the base of a glacier or ice shect. Reviews of Geophysics and Space Physics, Vol. 10, No. 1, p. 287-333.

Weertman, J., and Birchfield, G.E. 1983[a]. Basal water film, basal water pressure, and velocity of traveling waves on glaciers. Journal of Glaciology, Vol. 29, No. 101, p. 20-27.

Weertman, J., and Birchfield, G.E. 1983[b]. Stability of sheet water flow under a glacier. Journal of Glaciology, Vol. 29, No. 103 , p. 374-82.

Yale, D.P. Unpublished. Network modelling of flow, storage, and deformation in porous rocks. [Ph.D. thesis, Stanford University, 1984.]

\section{APPENDIX}

\section{HYDRAULIC GRADIENT IN CAVITY SYSTEM WITH CONSTRICTIONS}

In the main text, I derived an expression (Equation (11)) relating the flux $Q$ to hydraulic gradient $G$, sliding speed $u_{\mathrm{S}}$, cavity height $R$, effective pressure $p_{\mathrm{e}}$, and roughness $m$. If the water pressure is not so high that the cavities are nearly unstable, then a good approximation to Equation (11) is

$$
Q=\text { const. }\left[\frac{n A}{p_{\mathrm{e}}}\right)^{n} R^{5 / 3} u_{\mathrm{s}} G^{1 / 2} m^{-1}
$$

where $n$ and $A$ are the flow-law parameters (Nye, 1953).

Consider now a cavity containing constrictions as shown in Figure 3. In the steady state, the flux must be the same in both the "wide" and "narrow" sections of the cavity, hence from Equation $(\mathrm{A}-1)$

$$
\frac{R_{\text {wide }}^{5 / 3} G_{\text {wide }}^{1 / 2}}{p_{\mathrm{e} \text { 'wide }}^{n}}=\frac{R_{\text {narrow }}^{5 / 3} G_{\text {narrow }}^{1 / 2}}{p_{\mathrm{e}, \text { narrow }}^{n}}
$$




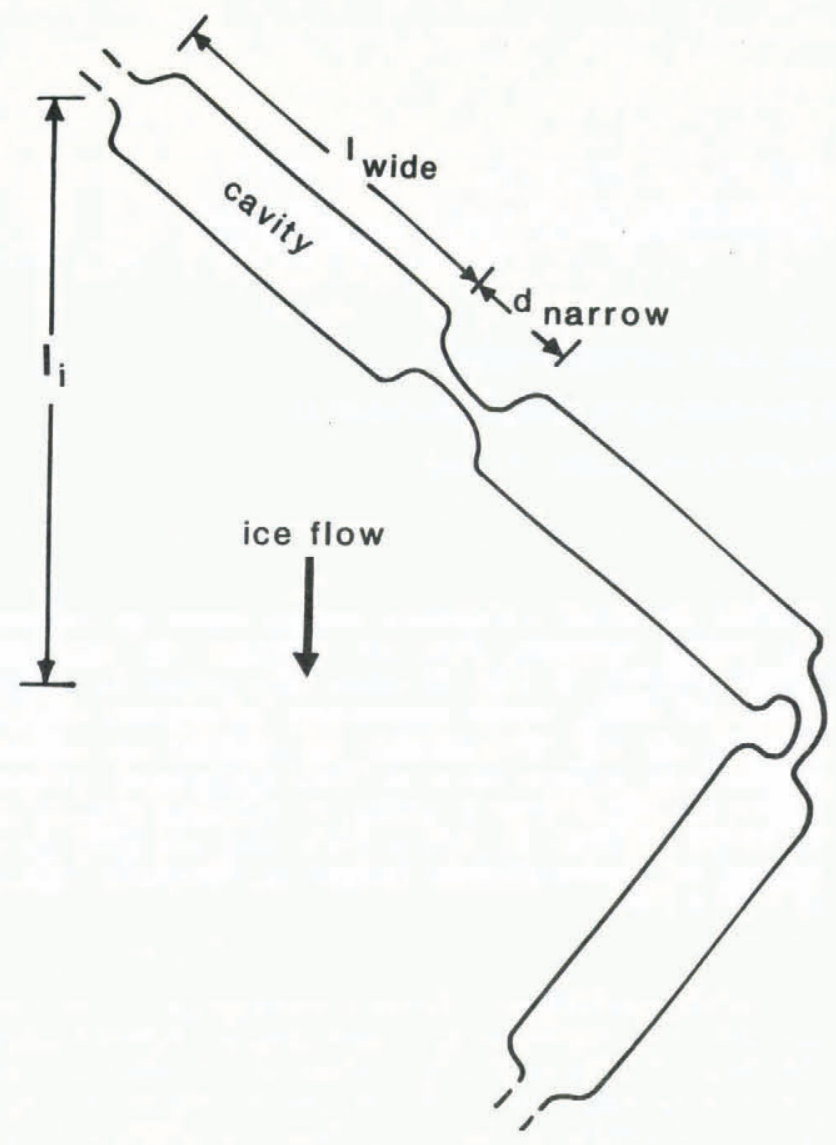

Fig. 3. Schematic view of cavity network with constrictions.

where I assume $m$ to be uniform along the cavity network. The relative values of the hydraulic gradients are therefore

$$
\frac{G_{\text {narrow }}}{G_{\text {wide }}}=\left[\frac{R_{\text {wide }}}{R_{\text {narrow }}}\right]^{10 / 3}\left[\frac{p_{\mathrm{e}}, \text { narrow }}{p_{\mathrm{e}} \text {, wide }}\right)^{2 n} .
$$

The difference in $p_{\mathrm{e}}$ between adjacent narrow and wide sections will not be large in comparison to $p_{\mathrm{e}}$, so to a good approximation

$$
\frac{G_{\text {narrow }}}{G_{\text {wide }}}=\left[\frac{R_{\text {wide }}}{R_{\text {narrow }}}\right]^{10 / 3} .
$$

It is clear from this expression that the hydraulic gradient in narrow constrictions may easily be one or two orders of magnitude greater than in wide parts of a cavity.

To estimate the actual value of $G_{\text {wide }}$, consider again Figure 3. The total drop in hydraulic gradient $\Delta \Phi$ through the combined narrow and wide parts of the cavity is

$$
\Delta \Phi=G_{\text {narrow }} l_{\text {narrow }}+G_{\text {wide }} l_{\text {wide }}
$$

where $l_{\text {narrow }}$ and $l_{\text {wide }}$ are the lengths of the respective cavity segments. The average hydraulic gradient $\langle G\rangle$ along the cavity network is therefore

$$
\langle G\rangle=\frac{\Delta \Phi}{l_{\text {narrow }}+l_{\text {wide }}}
$$

or using Equation (A-5)

$$
\langle G\rangle=\frac{G_{\text {narrow }} l_{\text {narrow }}+G_{\text {wide }} l_{\text {wide }}}{l_{\text {narrow }}+l_{\text {wide }}} .
$$

Now let $G_{\mathrm{i}}$ be the gradient that would apply for a conduit along the ice-flow direction, and let $\tilde{\tau}$ be the tortuosity of the actual cavity network, defined as

$$
\tilde{\tau}=\frac{l_{\text {narrow }}+l_{\text {wide }}}{l_{\mathrm{i}}}
$$

where $l_{\mathrm{i}}$ is defined in Figure 3. The average hydraulic gradient $\langle G\rangle$ along the cavity network may therefore also be expressed as

$$
\langle G\rangle=\frac{G_{i}}{\tilde{\tau}} .
$$

Equating the two expressions for $\langle G\rangle$ and using Equation $(A-4)$, one finds after a bit of algebra:

$$
G_{\text {wide }}=\frac{G_{i}}{\tau}\left[\frac{1+\left(\frac{l_{\text {narrow }}}{l_{\text {wide }}}\right]}{1+\left[\frac{l_{\text {narrow }}}{l_{\text {wide }}}\right]\left[\frac{R_{\text {wide }}}{R_{\text {narrow }}}\right]^{10 / 3}}\right] .
$$

Supposing, for example, that $\tilde{\tau}=2$ (perhaps an underestimate), $\quad l_{\text {narrow }} / l_{\text {wide }}=0.1$, and $R_{\text {wide }} / R_{\text {narrow }}=4$, one finds

$$
G_{\text {wide }} \approx 0.05 G_{\mathrm{i}} \text {. }
$$

It seems clear that the hydraulic gradient in the wide sections of the cavity may be only a very small fraction of the hydraulic gradient that would obtain in conduits along the ice-flow direction.

The mean flow rate $\bar{U}$ through the cavity network may also be readily related to the flow rates in the different sections. The time required for a "parcel" of water to traverse the narrow section is

$$
t_{\text {narrow }}=\frac{l_{\text {narrow }}}{U_{\text {narrow }}}
$$

and similarly for the wide sections,

$$
t_{\text {wide }}=\frac{l_{\text {wide }}}{U_{\text {wide }}}
$$

where $U_{\text {narrow }}$ and $U_{\text {wide }}$ are the flow rates for the respective sections. The mean flow rate $\bar{U}$ is defined as

$$
\bar{U}=\frac{l_{\text {narrow }}+l_{\text {wide }}}{t_{\text {narrow }}+t_{\text {wide }}} .
$$

Straightforward algebra leads to the result

$$
\frac{\bar{U}}{U_{\text {wide }}}=\frac{1+\left[\frac{l_{\text {narrow }}}{l_{\text {wide }}}\right]}{1+\left[\frac{l_{\text {narrow }}}{l_{\text {wide }}}\right]\left[\frac{U_{\text {wide }}}{U_{\text {narrow }}}\right]} .
$$
$U_{\text {wide }}$ must be less than $U_{\text {narrow }}$, so if $l_{\text {narrow }} / l_{\text {wide }} \ll 1$, one
finds that

$$
\bar{U} \approx U_{\text {wide }}
$$

